\title{
Prevalência de necrose tecidual após aplicação de ácido hialurônico
}

\author{
Prevalence of tissue necrosis after application of hyaluronic acid \\ Prevalencia de necrosis tisular tras la aplicación de ácido hialurónico
}

Maria Angélica Otero de Melo dos Reis ${ }^{1 *}$, Ana Júlia Moreno Rabelo², Ana Sara Negre Téo², Giulia Dalla Bernardina Cardoso ${ }^{3}$, Marcela Scardua Zanotti Guerra ${ }^{4}$, Mariana Olympio Rua ${ }^{3}$, Mariana Reis Chaves Bicalho $^{2}$, Martina Barina Araujo ${ }^{5}$, Tawany Tavares Santos Vasconcelos ${ }^{6}$, Milena Ferreira Gandra ${ }^{7}$

\section{RESUMO}

Objetivo: Analisar a produção científica recente sobre a necrose tecidual após a aplicação de ácido hialurônico, explorando a epidemiologia, patogênese, prevenção e tratamento desta complicação. Revisão bibliográfica: Constatou-se que a ocorrência de complicações após a aplicação de ácido hialurônico não é frequente e a maior parte dos eventos adversos são leves e autolimitados. Apesar de rara, a necrose tecidual desencadeada por preenchimento com ácido hialurônico é grave e importante, no entanto, as evidências são muito escassas quanto ao tratamento ideal. Para não desencadear o agravamento do problema, deve-se, a partir dos primeiros sinais e sintomas (dor, branqueamento da pele ou alterações de cor na distribuição do vaso sanguíneo regional), interromper imediatamente a aplicação e injetar hialuronidase o mais precoce possível, associado a compressas mornas e massagem local, para tentar aumentar o fluxo sanguíneo e dissolver o êmbolo. Considerações finais: No presente estudo, pode-se observar a importância do conhecimento profundo da anatomia vascular da face, bem como o treinamento adequado de médicos que usam preenchimentos injetáveis, visto que esse procedimento tem se tornado crescente nos consultórios de dermatologia.

Palavras-chave: Prevalência, Isquemia, Ácido hialurônico.

\begin{abstract}
Objective: Analyze the recent scientific production on tissue necrosis after the application of hyaluronic acid, exploring the epidemiology, pathogenesis, prevention and treatment of this complication. Bibliographic review: It was found that the occurrence of complications after the application of hyaluronic acid is not frequent and most adverse events are mild and self-limiting. Although rare, tissue necrosis triggered by filling with hyaluronic acid is serious and important, however, the evidence is very scarce regarding the ideal treatment. In order not to trigger the worsening of the problem, from the first signs and symptoms (pain, whitening of the skin or changes in color in the distribution of the regional blood vessel), immediately stop the application and inject hyaluronidase as early as possible, combined with warm compresses and local massage, to try to increase blood flow and dissolve the plunger. Final considerations: In the present study, it is possible to observe the importance of deep knowledge of the vascular anatomy of the face, as well as the adequate training of doctors who use injectable fillers, as this procedure has become increasingly common in dermatology offices.
\end{abstract}

Keywords: Prevalence, Ischemia, Hyaluronic acid.

\footnotetext{
1 Universidad Nacional de Rosario (UNR), Rosario, Santa Fe, Argentina.

*E-mail: mariaoteromeloreis@gmail.com

2 Centro Universitário Presidente Antônio Carlos (UNITPAC), Araguaína - TO.

3 Universidade Vila Velha (UVV), Vila Velha - ES.

${ }^{4}$ Centro Universitário do Espírito Santo (UNESC), Colatina - ES.

${ }^{5}$ Faculdade de Medicina de Campos (FMC), Campos Goyatacazes - RJ.

${ }^{6}$ Universidade Federal de Minas Gerais( UFMG), Belo Horizonte - MG.

${ }^{7}$ Centro Universitário de Caratinga, Caratinga - MG.
} 


\section{RESUMEN}

Objetivo: Analizar la producción científica reciente sobre necrosis tisular tras la aplicación de ácido hialurónico, explorando la epidemiología, patogénesis, prevención y tratamiento de esta complicación. Revisión bibliográfica: Se encontró que la aparición de complicaciones después de la aplicación de ácido hialurónico no es frecuente y la mayoría de los eventos adversos son leves y autolimitados. Aunque rara, la necrosis tisular desencadenada por el llenado con ácido hialurónico es grave e importante, sin embargo, la evidencia es muy escasa sobre el tratamiento ideal. Para no desencadenar el agravamiento del problema, desde los primeros signos y síntomas (dolor, blanqueamiento de la piel o cambios de color en la distribución de los vasos sanguíneos regionales), detenga inmediatamente la aplicación e inyecte hialuronidasa lo antes posible, combinado con compresas tibias y masaje local, para intentar aumentar el flujo sanguíneo y disolver el émbolo.Consideraciones finales: En el presente estudio se puede observar la importancia del conocimiento profundo de la anatomía vascular del rostro, así como la adecuada formación de los médicos que utilizan rellenos inyectables, ya que este procedimiento se ha vuelto cada vez más común en los consultorios de dermatología.

Palabras clave: Prevalencia, Isquemia, Ácido hialurónico.

\section{INTRODUÇÃO}

O preenchimento com ácido hialurônico $(\mathrm{AH})$ tem se popularizado nas últimas três décadas para o aumento do volume dos tecidos moles, visando rejuvenescimento da pele (BRAVO B, et al., 2015). Segundo a American Society of Plastic Surgeons (ASAPS), a partir de estudos realizados em 2019 com médicos certificados pela American Board of Medical Specialties (ABMS), os preenchimentos de tecidos moles (pele, tecido subcutâneo, tecido adiposo e músculo) com AH ocupam o segundo lugar entre os procedimentos cosméticos minimamente invasivos mais utilizados, ficando atrás apenas da toxina botulínica tipo A (ASAPS, 2019).

A utilização de outros métodos estéticos para contorno de face e lábios como: silicone, polimetilmetacrilato, ácido poli-láctico e hidroxiapatita de cálcio, foram contestados devido à grande incidência de efeitos adversos (EA) como: processos alérgicos, dor, exsudação e hematomas (BERNARDES IN, et al., 2018). Todavia, atualmente, o perfil de segurança associado ao preenchimento com AH injetável é favorável, sendo raros os efeitos indesejáveis após a sua aplicação, o que dificulta, muitas vezes, a conduta clínica frente a eles (ALMEIDA AT, et al., 2017).

A ocorrência de complicações após aplicação de $\mathrm{AH}$ não é frequente e a maior parte dos eventos adversos são leves (edema, eritema e equimoses locais) e autolimitados. Contudo, eventos mais graves como necrose e isquemia são passíveis de ocorrer. Apesar de rara, a necrose tecidual desencadeada por preenchimento com AH é grave e importante. A necrose é originada da interrupção do suprimento vascular por compressão vascular ou obstrução severa do leito vascular pela injeção direta do AH nos vasos (BRAVO BF, et al., 2015).

Segundo relatório publicado pela ASAPS, houve 2.160.578 procedimentos cosméticos de preenchimento com AH nos Estados Unidos em 2019. Esse valor representa cerca de 79,3\% de todos os preenchimentos de partes moles e $11 \%$ de todos os procedimentos cosméticos realizados no país. Também em 2019, foi constatado que $97 \%$ dos preenchimentos com AH foram realizados por mulheres e que $50 \%$ dos procedimentos foram feitos em pessoas com idades entre 40 e 54 anos (ASAPS, 2019).

O aumento da expectativa de vida, juntamente com os efeitos do envelhecimento cutâneo, despertam o interesse no rejuvenescimento da pele e os tratamentos não invasivos (laser, toxina botulínica e AH) geralmente são a primeira escolha. $\mathrm{O} A H$ é um preenchedor biodegradável, não permanente, que pode ser absorvido pelo organismo de 6 a 18 meses (SILVA DRM e CARVALHO GG, 2018).

Dessa forma, o objetivo do presente estudo consiste em analisar a produção científica sobre a necrose tecidual após aplicação de $\mathrm{AH}$, explorando a epidemiologia, patogênese, prevenção e tratamento desta complicação. 


\section{REVISÃO BIBLIOGRÁFICA}

\section{Epidemiologia}

A procura por procedimentos estéticos tem crescido consideravelmente, visto que foi designado pela sociedade contemporânea a associação do padrão de beleza à juventude (CASTRO MB e ALCÂNTARA GA, 2020). É importante destacar que o estudo do envelhecimento facial é de extrema importância, sendo alvo de pesquisa há muitos anos, logo, é notória sua grande evolução com o passar dos tempos.

Em 1934, dois farmacêuticos alemães, Karl Meyer e Jonh Palmer, isolaram no laboratório de Bioquímica do Departamento de Oftalmologia da Universidade de Columbia a enzima responsável pela produção do $\mathrm{AH}$, a partir do humor vítreo dos olhos bovinos. Ainda nesse mesmo ano, a enzima foi isolada a partir do cordão umbilical, por meio de extração aquosa com clorofórmio (BERNADES IN, et al., 2018).

$\mathrm{Na}$ década seguinte, ocorreu a descoberta de glicosaminoglicano e, então, Meyer dedicou-se ao isolamento do $\mathrm{AH}$ de tecidos animais, incluindo o fluido sinovial, a pele, o cordão umbilical e a crista de galo, a partir de um procedimento de remoção de proteínas por desnaturação ou digestão proteolítica. Vale destacar, que esse procedimento obtinha muitos traços de proteínas e endotoxinas, sendo necessária a realização de um processo de purificação através da utilização de agentes químicos. Atualmente, a obtenção de AH ocorre por meio de processos biotecnológicos, a partir da produção microbiana. A cepa da espécie de bactérias Streptococcus zooepidemicus, em condições adequadas, produz cerca de $7 \mathrm{~g} / \mathrm{l}$ de AH ( SILVA DRM e CARVALHO GG, 2018).

Diante do avançar da procura por procedimentos estéticos em todo o mundo, a aplicação injetável com AH constitui um dos procedimentos estéticos com maior procura, visando a harmonização facial e o rejuvenescimento (CASTRO MB e ALCÂNTARA GA, 2020). Ressalta-se, de acordo com a Sociedade Internacional de Cirurgia Plástica (IASP), que foram realizados 254 mil procedimentos com a aplicação de $A H$ no Brasil em 2017. Portanto, é perceptível que o AH teve grande impacto e destaque no mercado brasileiro devido à sua alta eficácia e segurança (ALMEIDA AT, et al., 2017).

Sabe-se que a incidência de eventos adversos por esse método é baixa, no entanto, quando acontecem, estão relacionadas principalmente à técnica de aplicação e falta de higienização adequada. O maior índice de intercorrências ocorre nas regiões sulco nasolabial, sulco nasogeniano e sulco glabelar, por consequência da irrigação dos ramos internos da artéria carótida. Outras regiões acometidas são forame supraorbital, supratroclear e região mentoniana, a maioria leve e de duração limitada, manifestando eritema, edema e equimose locais. Relata-se, ainda, eventos graves com necrose e isquemia (BRAVO B, et al., 2015; ALMEIDA AT, et al., 2017).

A necrose representa um evento raro, mas de grande importância, com maior prevalência quando o AH é injetado na glabela, considerado local de maior risco de necrose em decorrência da compressão local ou injeção intra-arterial na artéria supratroclear e seus ramos. A segunda área com a mais alta expressividade de casos é no sulco nasolabial, como consequência da compressão local ou também a injeção intra-arterial na artéria supratroclear e seus respectivos ramos (SANTONI MA, 2018).

\section{Patogênese da necrose}

A necrose é resultado da interrupção do suprimento vascular local, por obstrução arterial ou venosa, que desencadeia morte celular por hipóxia e, consequentemente, morte tecidual (BRAVO BSF et al., 2015). Os principais fatores que proporcionam essa interrupção seriam: a obstrução franca vascular, ao injetar de forma direta o AH na luz do vaso; a compressão arterial externa pelo produto ou edema; e a presença de lesão vascular (BRAVO BF, et al., 2015; VASCONCELOS SB, et al., 2020).

A oclusão arterial aguda pelo preenchimento com AH é responsável pela maioria dos casos de necrose cutânea por isquemia. Os danos podem ser locais e causar cicatrizes e desfigurações ou, em casos mais raros, a substância pode ser transportada pelos vasos de forma retrógrada. Com isso, o produto pode formar êmbolos, causando isquemia em uma segunda área, a exemplo da cegueira embólica e do acidente vascular cerebral (ALLEN S, 2019). O paciente pode apresentar como sinal da embolização: dor, palidez local, livedo 
reticular que evolui para a formação de bolhas, úlceras e necrose tecidual. Com exceção da cegueira, a oclusão vascular ocorre em até 3 em 1.000 e é mais comum em enchimentos não-HA. Sinais e sintomas podem ser discretos, mas incluem dor fora de proporção ou branqueamento (DAHER JC, et al., 2019; CROCCO El, 2012).

Já oclusão da artéria retiniana é um evento raro que ocorre quando o preenchimento dérmico entra na circulação ocular por meio retrógrado do fluxo arterial após injeção intra-arterial inadvertida em um dos ramos distais da artéria oftálmica. Estes incluem a artéria angular e as artérias zigomático temporal, zigomático facial e dorsal nasal. As artérias supratroclear e supraorbital também são terminais ramos da artéria oftálmica(FUNT D e PAVICIC T, 2013).

Quando há uma injeção intravascular em uma dessas artérias, que excede pressão intra-arterial, o injetado pode se mover de maneira proximal para a origem da artéria retiniana central; quando a pressão é liberada, o material se move distalmente para a retina artéria, bloqueando o suprimento de sangue para a retina e potencialmente causando deficiência visual ou cegueira. Imediatamente pode ocorrer embaçamento ou perda de visão (FUNT D e PAVICIC T, 2013). Em caso de suspeita de necrose da artéria oftálmica, é recomendado entrar em contato de forma imediata com o oftalmologista (BERNARDES IN, et al., 2018; BRAVO BF, et al., 2015).

A maior parte do rosto é fornecida por ramos da artéria carótida externa, exceto pela testa, a parte central entre os olhos e a parte superior do nariz, que são fornecidas pela artéria oftálmica, e um ramo da artéria carótida interna. As artérias envolvidas em complicações da glabella e da testa são as artérias supratrocráxares e supraorbitais, ambas podem levar a complicações relacionadas aos olhos. A artéria supratrochlear é constante na maioria dos casos, variando sua posição em um máximo de $5 \mathrm{~mm}$. Ele começa profundamente na parte superomedial da órbita e torna-se subcutâneo 15 a $25 \mathrm{~mm}$ da cordilheira supraorbital à medida que se move superiormente. A artéria supraorbital aparece na borda supraorbital, vertical à pupila, tornando-se subcutânea de 15 a $20 \mathrm{~mm}$ acima da crista orbital, indo em direção à testa(DAHER JC, et al., 2020).

O preenchimento da região nasal deve ser realizado no plano supraperiosteal profundo, abaixo do SAMS, evitando assim a rede venosa anastomótica.A necrose tecidual ocorre mais na chamada zona de risco, que é o nariz, principalmente na glabella. A glabella é fornecida por artérias do supratroquista, que viaja em um caminho medial até as sobrancelhas. Devido a este curso anatômico, sugere-se que há um risco maior de que a injeção intra-arterial inadvertida possa ocorrer12. A topografia alar do nariz é altamente vascularizada por ramos em sua maioria terminais da artéria angular, um região que apresenta poucas em ramos colaterais, e por este motivo se apresenta como uma área comum de necrose do tecido local. A maioria dos casos ja apresentados na literatura ocorreu na em regiões asitáticas, onde se apresenta uma prevalência de preenchimento em áreas faciais de risco (DAHER JC, et al., 2020).

A oclusão venosa é atípica, mas pode ocorrer onde previamente já existia algum grau de obstrução. Pode ocorrer, ainda, em locais onde foi infiltrada uma grande quantidade de volume material, principalmente onde há significativa tensão e o tecido está restrito, como em cicatrizes, cujo tecido não apresenta uma elasticidade comum (DAHER JC, et al., 2019). As oclusões venosas geralmente manifestam sintomas de forma mais tardia, apresentando-se com menor dor local e com manifestações cutâneas de evolução lenta, tal como tom azulado na pele (CROCCO El, 2012).

Os fatores de risco associados à aplicação intravascular de ácido hialurônico são: áreas injetadas (locais próximos ao de vasos conhecidos ou injeção profunda), tamanho da haste da agulha (as de menor diâmetro têm uma tendência maior a penetrar o lúmen do vaso), cicatriz prévia (causa estabilização e fixação das artérias no lugar, o que favorece a penetração desses vasos por agulhas) e volume do produto (a quantidade é diretamente proporcional à possibilidade de obstrução vascular) (BRAVO BF, et al., 2015; PARADA MB, et al., 2016).

De maneira geral, as complicações mais graves, tal como a necrose tecidual, após a aplicação de AH, estão majoritariamente associadas ao desconhecimento da anatomia facial pelo profissional, principalmente 
das estruturas vasculares e nervosas da face (CASTRO MB e ALCÂNTARA GA, 2020). A inexperiência do aplicador, além da técnica incorreta e das nuances do próprio produto também são fatores relacionados com efeitos adversos, como a isquemia tecidual (SANTONI MTS, 2018).

\section{Prevenção da necrose tecidual decorrente do uso de $\mathbf{A H}$}

A primeira estratégia contra complicações vasculares do uso de HA é a prevenção. O médico deve ter conhecimento sobre a anatomia vascular da topografia, onde ocorre a infiltração do material. Durante uma visita inicial, é fundamental que os pacientes questionem sua experiência com procedimentos faciais anteriores (DAHER JC, et al., 2020). A presença de um profissional capacitado que realize uma avaliação cuidadosa do paciente e tenha pleno conhecimento da anatomia e fisiologia facial, a fim de evitar aplicação em regiões de maior risco, como as regiões com alta vascularização sanguínea que apresentam maiores chances de evoluir para complicações vasculares, reações inflamatórias e formação de nódulos. Outro ponto importante é evitar associação com outros procedimentos, pois o risco de complicações em tecido previamente traumatizado é superior (VASCONCELOS SB, 2020).

Vale destacar que grande parte das complicações poderiam ser evitadas por meio de medidas preventivas eficazes. Para injeções superficiais, uma técnica de rosca linear é defendida com pequenas alíquotas do produto de forma anterograda e retrógrada. Fanning ou crosshatching também pode ser aconselhado a permitir até mesmo a distribuição do produto. Com uma colocação mais profunda, uma técnica de injeção de depósito tem sido tradicionalmente recomendada. Deve-se estar sempre ciente do local da ponta da agulha para evitar a colocação inadvertida. As zonas de anatomia e perigo facial devem ser respeitadas para garantir uma entrega segura no avião alvo (ROHRICH RJ, et al., 2019).

Em relação à escolha de microcânulas ou agulhas, deve-se ficar atento e optar por uma de menor calibre, uma vez que ela irá apresentar menor velocidade de injeção, tornando menos provável a oclusão vascular e o bloqueio do fluxo periférico. Ademais, é aconselhável utilizar agulhas ou cânulas rombas ao invés de agulha afiada e movê-la com suavidade, a fim de prevenir lacerações (GUTMANN IE e DUTRA RT, 2018). Além disso, destaca-se a importância da realização da regurgitação antes de iniciar o procedimento para prevenir que a agulha se encontre em uma artéria ou veia e evitar a injeção de grande volume numa única sessão, devido à sua associação com inflamação posterior (MONTEIRO EO, 2016).

O uso de cânulas para injeção profunda é outra recomendação, pois é menos provável que uma cânula fina de ponta cega penetrou em uma artéria em comparação com uma agulha. É prudente sempre aspirar antes de se infiltrar no material e ao retirar a agulha. Evite a infiltração de um volume muito grande $(<0.1)$ do material a uma pressão exagerada, usando seringas menores para controle de fluxo, para evitar uma possível reversão do fluxo e embolia retrógrada (DAHER JC, et al., 2020).

As áreas mais vulneráveis são aquelas em que o suprimento de sangue depende fortemente de uma única artéria ramo (padrão axial de fornecimento de sangue) (FUNT D e PAVICIC T, 2013). Seis zonas de perigo facial foram descritas, o que aumenta o risco de comprometimento vascular. Estes incluem a glabella, templo, região infraorbital, lábios, dobra nasolabial e nariz. Essas áreas têm nomeado ramos arteriais, que merecem considerações anatômicas e cautela ao injetar nessas regiões para evitar complicações graves.Os princípios gerais para injeção segura de enchimento estão listados na Figura 1 (ROHRICH RJ, et al., 2019).

Figura 1 - Princípios para injeções seguras de enchimento.

Preenchimentos reversíveis (HA)
Agulhas pequenas ( 27 ou $30 \mathrm{G})$
Injeção anterógrarada / retrógrada
Seringas pequenas $\left(<1 \mathrm{~cm}^{3}\right)$
Injeções de baixa pressão
Cuidado nas regiões com cicatrizes / trauma anterior
Conhecimento da anatomia regional
Hialururonidasase disponível em todos os momentos

Fonte: Reis MA, et al., 2021; dados extraídos de American Society of Plastic Surgeons, 2017. 


\section{Tratamento}

O reconhecimento de um evento vascular e um tratamento rápido e agressivo é necessário para evitar complicações graves e potencialmente irreversíveis. Injeção de preenchimento em uma artéria pode causar necrose de tecidos em ambos os modos: anterógrada e retrógrada Anterógrada seria quando o êmbolo seguisse o trajeto arterial, ou seja, ao aplicar o preenchedor a agulha ou cânula pode perfurar acidentalmente a parede de um dos ramos distais e entrar no lúmen da artéria. Se a ponta da agulha ou cânula estiver no lúmen de uma artéria quando o êmbolo for injetado, ele seguirá o trajeto da artéria de maneira anterógrada. Já a forma retrógrada seria quando esse êmbolo seguisse o trajeto contrário da artéria, através da pressão forçada que irá aplicar-se na seringa (FUNT D e PAVICIC T, 2013).

Embora existam protocolos para o tratamento de complicações vasculares com o uso de ácido hialurônico, as evidências são muito escassas quanto ao tratamento ideal (CROCCO El, 2012). O primeiro passo é identificar os sinais e sintomas que devem levar o profissional a interromper imediatamente a injeção, que são: dor (poderá demorar várias horas devido à presença de anestésico local misturado em grande parte dos preenchedores), branqueamento da pele (ocorrerá durante a injeção e durará apenas alguns segundos, seguido de livedo) ou alterações de cor (livedo, coloração azul ou cinza) na distribuição do vaso sanguíneo regional. É sugerido realizar a compressão digital da área para avaliar o retorno sanguíneo, que se maior que um a dois segundos, sugere insuficiência arterial (ALLEN S, 2019; PARADA MB, 2016).

E se houver qualquer evidência de problema visual após a injeção facial de um preenchedor dérmico, a consulta imediata com um oftalmologista é essencial (FUNT D e PAVICIC T, 2013). É consenso na literatura a injeção de hialuronidase o mais precoce possível, após as primeiras 24 horas do procedimento (CROCCO El, 2012; DAHER JC, et al., 2019), de preferência nas primeiras 4 horas (DAHER JC, et al., 2019; ALLEN S, 2019). Não há uma padronização quanto a dosagem do produto a deve ser utilizada, porém sabe- se que é importante evitar a subdose, sendo aconselhado infiltrar entre 450 e $1500 \mathrm{UI}$ em toda área afetada (DAHER JC, et al., 2019). Esse procedimento deve ser seguido de compressas mornas, e massagem local, para tentar para aumentar o fluxo sanguíneo e dissolver o êmbolo (GUTMANN IE e DUTRA RT, 2018; ALLEN S, 2019; DAHER JC, et al., 2019). Deve-se, ainda, reavaliar constantemente a possibilidade de nova infiltração, visto que a hialuronidase é degradada, diluída com fluido extracelular e difundida no tecido, diminuindo a sua concentração com o tempo no tecido afetado (DAHER JC, et al., 2019).

A hialuronidase é contra-indicada em pacientes alérgicos a picadas de abelha (BRAVO BF, et al., 2015) e pode ser necessária em doses maiores em pacientes que fazem uso de medicamentos com corticoides, estrogênios, salicilatos, hormônio adrenocorticotrópico e anti-histamínico, uma vez que essas medicações são mais resistentes à ação da hialuronidase (GUTMANN IE e DUTRA RT, 2018).

Existem outros tratamentos propostos, porém a eficácia ainda não é comprovada. Entre eles está o uso da prostaglandina $E 1$, pomada de nitroglicerina e oxigênio hiperbárico, aspirina, sildenafil e prednisona (ALLEN S, 2019). A medicina hiperbárica pode ser considerada em casos de necrose cutânea maciça iminente, uma vez que atua carreando oxigênio para os tecidos. (DAHER JC, et al., 2019; BRAVO BF, et al., 2015).

\section{CONSIDERAÇÕES FINAIS}

É crescente a aplicação de preenchedores de AH devido aos bons resultados apresentados, quando bem indicados, associado ao baixo índice de complicações. Todavia, o risco de falha na aplicação existe e pode causar lesões graves e irreversíveis. Uma das complicações mais temidas é a necrose tecidual, que ocorre principalmente por falta de conhecimento profundo da anatomia vascular, técnica incorreta ou características inadequadas do próprio produto. É necessário ser capaz de reconhecer os sinais e sintomas precoces da oclusão vascular e ter um plano de tratamento local. Uma das opções usadas na atualidade, mas não reconhecida pela ANVISA, é a aplicação de hialuronidase. O conhecimento sobre técnicas de reversão de necrose tecidual ainda é escasso, logo são necessários estudos futuros nessa área, uma vez que o mercado desse procedimento apresentou um crescimento exponencial nos últimos anos. 


\section{REFERÊNCIAS}

1. ALMEIDA AT, et al. Diagnóstico e tratamento dos eventos adversos do ácido hialurônico: recomendações de consenso do painel de especialista da America Latina. Surg Cosmet Dermato, 2017; 9(3): 204-13.

2. AMERICAN SOCIETY OF PLASTIC SURGEONS (ASPS). Plastic Surgery Statistics Report 2019. Disponível em: https://www.plasticsurgery.org/documents/News/Statistics/2019/plastic-surgery-statistics-full-report-2019.pdf. Acesso em 8 de novembro de 2020.

3. ARAÚJO AMR, et al. Efeitos adversos do ácido hialurônico no preenchimento facial. Mostra Científica da Farmácia, 2018; 5(1).

4. BERNARDES IN, et al. Preenchimento com ácido hialurônico. Revista Saúde em foco, 2018; 10: 603-612.

5. BRAVO BSF, et al. Delayed-type necrois after soft-tissue augmentation with hyaluronic acid. The Journal of Clinical and Aesthetic Dermatology, 2015; 8(12): 42-47.

6. CASTRO MB, ALCÂNTARA GA. Efeitos adversos no uso do ácido hialurônico injetável em preenchimentos faciais. Brazilian Jornal of health Review, 2020; 3(2): 2995-3004.

7. CROCCO El, et al. Eventos adversos do ácido hialurônico injetável Adverse events in injectable hyaluronic acid. Educação Médica Continuada, 2012; 4(3), 259-63.

8. DAHER JC, et al. Complicações vasculares dos preenchimentos faciais com ácido hialurônico: confecção de protocolo de prevenção e tratamento. Revista Brasileira de Cirurgia Plástica, 2020; 35(1): 2-7.

9. GUTMANN IE, DUTRA RT. Reações adversas associadas ao uso de preenchedores faciais com ácido hialurônico. Revista Eletrônica Biociências, Biotecnologia e Saúde, 2018; 11(20): 7-17.

10. FUNT D, PAVICIC T. Dermal fillers in aesthetics: an overview of adverse events and treatment approaches. Clinical, Cosmetic and Investigational Dermatology. 2013; 6: 295-316.

11. LEE JAE, et al. Necrose da pele com paralisia do nervo oculomotor devido a uma injeção de preenchimento de ácido hialurônico. Archives of Plastic Surgery, 2017; 44: 340-343.

12. MONTEIRO EO. Complicações imediatas com preenchimento cutâneo. Revista Brasileira de Medicina, $2014 ; 71$ : n.esp. $g 3$.

13. PARADA MB, et al. Manejo de complicações de preenchedores dérmicos. Surgical Cosmetic Dermatology, 2016; 8 (4): 342- 351.

14. ROHRICH RJ, et al. Abordagem prática e segurança de preenchimentos do ácido hialurônico. PRS Global Open, 2019.

15. SANTONI, MTS. Uso do ácido hialurônico injetável na estética facial: uma revisão de literatura. Dissertação Universidade regional Unijuí, 2018, 23 p.

16. SHAWN A. Anatomic danger zones for facial injection of soft tissue fillers. UpToDate, 2019, acesso em 05 de novembro de 2020.

17. SILVA DRM, CARVALHO GG. 2018. A atuação do ácido hialurônico e do polimetilmetacrilato em um estudo comparativo entre vantagens, desvantagens e efeitos adversos de cada preenchedor.

18. SINGH M, et al. Optical coherence tomography as a tool for real-time visual feedback and biomechanical assessment of dermal filler injections: preliminary results in a pig skin model. Exp Dermatol. 2016; 25(6): 475-6.

19. VASCONCELOS S, et al. O uso do ácido hialurônico no rejuvenescimento facial. Revista Brasileira Militar de Ciências, 2020; 6(14): 8-15.

20. WANG Q, et al. Vascular Complications After Chin Augmentation Using Hyaluronic Acid. Aesthetic Plastic Surgery, 2018; 42: 553-559. 